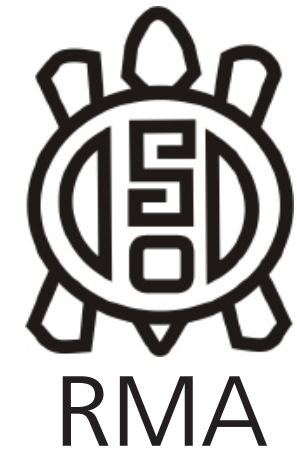

Antropología Social

\title{
Los lindes de la interculturalidad: Patrimonio, violencia institucional y derechos humanos en la política indigenista Argentina (2016-2019)
}

\author{
The boundaries of interculturality. Heritage, institutional violence and \\ human rights in indigenist policy Argentina (2016-2019) \\ Carolina Crespo*
}

* CONICET, Instituto Nacional de Antropología y Pensamiento Latinoamericano, Universidad de Buenos Aires, Argentina. E-mail: carolcres @hotmail.com

\begin{abstract}
Resumen
En este trabajo examino la manera en que violencia, derechos humanos y patrimonio indígena fueron tensionándose y acomodándose en las políticas "interculturales" implementadas en Argentina entre los años 2016 a 2019. Para ello, más que analizar cómo se construye o qué es el patrimonio, abordo al patrimonio instituido como derecho humano en un doble aspecto. Por un lado, en su carácter metacultural; esto es, como campo de reflexión acerca de la cultura misma. La acentuación evaluativa y afectiva de ciertos valores, conocimientos, historias y experiencias como patrimoniales se funda en y, paralelamente, delimita una visión del mundo que dirime la cultura propiamente dicha en cada momento. Por otro lado, lo examino a partir de su facultad performativa; de aquello que el patrimonio hace en el marco de patrones de gobernanza de una oligarquía que combinó neoliberalismo y conservadurismo en Argentina. El propósito último de estas consideraciones es poner de manifiesto ciertas aristas de la política indigenista de estos últimos años que fueron soslayadas y contribuir a la discusión sobre las políticas patrimoniales $y$ de derechos humanos como modalidades de convivencia intercultural.
\end{abstract}

Palabras clave: Patrimonio; Derechos humanos; Violencia institucional; Políticas indigenistas (2016-2019)

\begin{abstract}
In this paper I examine the way in which violence, human rights and indigenous heritage were being stressed and accommodated in the "intercultural" policies implemented in Argentina between 2016 and 2019. In order to do this, rather than analyzing how heritage is built or what it is, I approach the heritage instituted as a human right in a double aspect. On the one hand, relieving its metacultural character, that is, the reflections it puts into play about culture. The evaluative and affective accentuation of certain values, knowledge, stories and experiences as heritage is based on and, in parallel, delimits a vision of the world that defines the culture itself at all times. On the other hand, on its performative faculty; in what heritage does in the framework of governance patterns of an oligarchy that combined neoliberalism and conservatism in Argentina. The ultimate purpose of these considerations is to highlight some edges of the indigenist policy of recent years that was not taken into account and contribute to the discussion of heritage and human rights policies as modalities of intercultural coexistence.
\end{abstract}

Keywords: Heritage; Human rights; Institutional violence; Indigenist policy (2016-2019)

El año 2017 se caracterizó - parafraseando a un periodistapor fuertes embestidas contra los pueblos indígenas cuya visibilidad mediática y en redes alcanzó una dimensión inusitada. En el verano de ese año, el gobierno nacional de Mauricio Macri -que había asumido la presidencia dentro de la coalición política "Cambiemos" en diciembre de 2015- junto al gobierno provincial de Chubut en Patagonia, llevan adelante una feroz represión a la $P u$ Lof en Resistencia Cushamen. Hacía dos años, esta comunidad mapuche había iniciado la recuperación del espacio territorial de un sector de las tierras que en
1990, en el marco de políticas neoliberales, habían sido vendidas a manos del grupo Benetton. ${ }^{1}$ Desde hace varios años atrás, comunidades mapuche de distintas regiones de Patagonia han encarado recuperaciones territoriales bajo el propósito de retornar a aquellos espacios que les fueron arrebatados a sus familiares consanguíneos por parte de agencias estatales, estancieros, comerciantes y/o bien empresarios. En esta oportunidad, la recuperación

${ }^{1}$ Sobre la historia de este extenso territorio desde fines de siglo XIX, véase Minieri (2006). 
no se fundamentaba en ello sino en el derecho histórico como pueblo mapuche sobre un territorio que les ha sido expropiado con posterioridad a la "Conquista del desierto" a fines del siglo XIX (Muzzopappa y Ramos, 2017).

Desde los inicios de dicha recuperación se habían sucedido una serie de conflictos, acusaciones, allanamientos y represiones a la comunidad en los que habían intervenido las fuerzas de seguridad y la justicia. Pero la violenta represión de gendarmería nacional y de la policía provincial, disparando a hombres, mujeres y niños de la comunidad, destruyendo sus casas y deteniendo a varios de ellos en enero de 2017 y, especialmente la siguiente represión de gendarmería desplegada en el mes de agosto, alcanzaron alta repercusión a escala nacional. En agosto, miembros de esta lof y otros jóvenes no indígenas cortan la ruta como medida de reclamo por la liberación del longko de la comunidad, Facundo Jones Huala, que había sido acusado de terrorista. El gobierno nacional, con el aval de la provincia, inicia un operativo represivo hacia estos manifestantes y durante la represión, desaparece Santiago Maldonado, un joven no indígena que había ido a apoyar aquel reclamo. Dos meses más tarde su cuerpo aparece ahogado. El evento y la desaparición seguida de muerte de Santiago Maldonado conmocionaron al país y trascendieron al ámbito internacional. Al poco tiempo, en el mes de noviembre, otra comunidad mapuche -la lof Lafken Winkul Mapu- que había ido a recuperar territorio cerca del Lago Mascardi dentro del Parque Nacional Nahuel Huapi (provincia de Río Negro), era violentamente desalojada en varios operativos protagonizados por numerosos uniformados de la policía federal y la prefectura. A lo largo de esos días se sucedieron una serie de detenciones seguidas de violencia a mujeres y niños y, durante la represión del 25 de noviembre encarada por la prefectura, moría asesinado Rafael Nahuel, un joven de 22 años.

Ambos eventos devinieron en la judicialización penal de muchos mapuche de esa región, la constante presencia de fuerzas de seguridad en caminos y rutas de la zona, la irrupción de éstas en muchas comunidades mapuche y la difusión nacional de una fuerte estigmatización y discriminación indígena en redes sociales y en la mayor parte de los medios de comunicación -en especial, en aquellos de mayor tirada que apoyaban enfáticamente las medidas del nuevo gobierno. La violencia institucional sobre los indígenas, quiero aclarar, no es novedosa ni se circunscribe sólo a estos dos casos de Patagonia. Aun sin haber tenido demasiada difusión mediática, algunos gobiernos provinciales desalojaron violentamente, en este mismo período, a familias indígenas en otras regiones e, incluso, fueron denunciadas muertes de indígenas producto de la falta de atención básica de salud en el norte argentino. Asimismo, durante la gestión del gobierno anterior también se habían puesto en juego mecanismos represivos hacia indígenas por parte de algunos gobiernos provinciales, como por ejemplo en Formosa (Cardin, 2013; Soria, 2019).
Sin duda, las experiencias de violencia, muertes y judicializaciones han sido prácticas continuas de Estado que trascienden administraciones de gobierno y tienen larga data. Pero una diferencia notable del gobierno nacional de "Cambiemos" fue la apología que hizo del accionar represivo y la escalada de estigmatizaciones, racializaciones y discriminaciones que salieron a la luz en la voz de altos funcionarios del poder ejecutivo y algunos legisladores. Junto a viejos estereotipos ya vigentes en la Generación de 1880 que justificaron la Conquista al Desierto -como la clasificación del "indígena violento" que saquea bienes (Delrio, 2018) o bien del mapuche como extranjero-, se difundieron otras estigmatizaciones que diferenciaban a los "indios verdaderos" y "dóciles" de aquellos considerados "truchos", "oportunistas" y/o "terroristas". La clasificación de "terroristas" a la población indígena era novedosa en nuestro país y se enmarcaba en la Ley Antiterrorista Argentina, sancionada en el año 2007 y luego modificada en algunos aspectos en el año 2011.2

Tanto periodistas como funcionarios de alta jerarquía política -el presidente y vicepresidenta, algunos ministros, gobernadores y legisladores- sostuvieron aquellos estigmas y/o asociaron a estos mapuche con la figura de "terroristas", justificando el accionar represivo del poder ejecutivo y la judicialización implementada sobre estos sujetos entendidos como un "peligro o amenaza al orden", la "seguridad de las personas" y el "progreso nacional". Asimismo, amplios sectores de la sociedad adhirieron a estas imágenes que lograban sedimentar, en parte porque se montaban sobre estereotipos de largo arraigo; pero también, porque aquellas categorizaciones como la del "terrorista", se echaron a circular -como sostienen Muzzopappa y Ramos (2017)- junto a una serie de descripciones, difamaciones e imágenes que fueron rápidamente asociadas a la clandestinidad y la violencia.

Ahora bien, todos estos dispositivos -represión, judicialización y estigmas- se desplegaron el mismo año en que debía consensuarse la tercera prórroga de la Ley Nacional N²6160, cuyo objetivo era relevar el territorio indígena en todo el país, e impedir el desalojo de comunidades indígenas durante el período en que el relevamiento estuviese en funcionamiento. ${ }^{3}$ Pero también

\footnotetext{
2 Esta ley fue dictada como producto de exigencias de organismos internacionales para evitar el lavado de dinero como fuente de financiamiento del terrorismo internacional. En el año 2011, a raíz de las polémicas locales que la ley desató, centradas en la posibilidad de que la protesta fuese criminalizada bajo esta figura delictiva, se introdujo un párrafo al artículo 41 quinquies que establece que "Las agravantes previstas en este artículo no se aplicarán cuando el o los hechos de que se traten tuvieren lugar en ocasión del ejercicio de derechos humanos y/o sociales o de cualquier otro derecho constitucional". Sin embargo, la ley intentó ser aplicada en el ámbito judicial cuando la pu lof en Resistencia Cushamen hacía poco tiempo había iniciado el proceso de recuperación territorial. Sobre la cronología de lo sucedido allí, véase https://apdh.org.ar/areas/pueblos-originarios/dossier.pu.lof

${ }^{3}$ Esta ley se promulga en el año 2006. Se trata de una ley de emergencia que dispone, por el término de 4 años, la realización del relevamiento
} 
tenían lugar en el marco de un gobierno que desde el año 2016 había traspasado al Instituto Nacional de Asuntos Indígenas -de aquí en adelante INAI- al Ministerio de Justicia y Derechos Humanos; algo que la arrolladora beligerancia de aquellos hechos hizo que pasara inadvertido incluso por la mirada de los académicos que fueron reflexionando sobre las políticas indigenistas ${ }^{4}$ recientes.

En este marco, este trabajo propone compartir algunas consideraciones respecto a este escenario. Reflexiona sobre la manera en que violencia, derechos humanos y patrimonio indígena fueron tensionándose y acomodándose en las políticas "interculturales" implementadas en Argentina entre los años 2016 a 2019. Dado que una de las políticas del gobierno nacional de ese entonces se centró en la difusión visual de la gestión de cada institución del Estado a través de medios tecnológicos -redes y páginas web-, el análisis que sigue se basa en los efectos del montaje de discursos e imágenes repetidas y faltantes vehiculizados por parte del INAI en esa etapa. El propósito último de estas consideraciones es doble: poner de manifiesto aristas de la política indigenista de estos últimos años que fueron soslayadas y contribuir a la discusión sobre las políticas patrimoniales y de derechos humanos como modalidades de convivencia intercultural.

\section{Tópicos y ejes para la discusión}

Mientras las políticas patrimoniales fueron amplificándose y constituyéndose en una de las modalidades de tratamiento y construcción de lo que se ha ido definiendo como "diversidad" (Crespo et al, 2007), los debates que en otras épocas se trataban apelando al concepto de "cultura", "tradición", saberes", fueron enmarcándose y discutiéndose cada vez más en términos de "patrimonio" (Macdonald, 2013). En efecto, en el marco de lo que se ha denominado como políticas multiculturales o interculturales neoliberales, el patrimonio, en tanto dispositivo pedagógicamente orientado, ha sido alcanzado por nociones tales como "diversidad cultural" e "interculturalidad" que operan, en palabras de Boccara

técnico-jurídico-catastral de la situación dominial de las tierras ocupadas por las comunidades indígenas y garantiza la suspensión de desalojos a dichas comunidades durante el período de vigencia de la misma. El Instituto Nacional de Asuntos Indígenas ha sido el encargado de promover el relevamiento con "el Consejo de Participación Indígena, los Institutos Aborígenes Provinciales, Universidades Nacionales, Entidades Nacionales, Provinciales y Municipales, Organizaciones Indígenas y Organizaciones no Gubernamentales" (artículo 3). Diversas razones lentificaron el cumplimiento del relevamiento, por lo cual, la ley fue prorrogada en el año 2009 (Ley N²6554), en el 2013 (Ley Nº 26894) y en el 2017 (Ley N²7400). Asimismo, aun cuando esta ley ha sido aplicada favorablemente en sentencias judiciales para impedir desalojos a comunidades indígenas, varios informes han denunciado la persistencia de desalojos con posterioridad a su entrada en vigencia (Anaya, 2012) así como la reducción y desplazamiento de los espacios territoriales de comunidades indígenas como consecuencia del avance de la frontera agropecuaria, especialmente en el Este de la provincia de Salta (Barberi, 2015; Braticevic y Cabana, 2014).

${ }^{4}$ Con el término "política indigenista" me refiero a la distinción realizada por Lenton (2010) respecto a la política estatal indígena.
(2012), como lucha de clasificaciones vis a vis de modalidades de convivencias. Dentro de este paraguas, estas políticas se asentaron sobre dos concepciones del patrimonio: sobre la idea del patrimonio como recurso para el desarrollo o capital para poblaciones vulnerables y, más recientemente, sobre la noción del patrimonio como un derecho humano. Pero su abordaje diferenciado ha llevado en ocasiones a dicotomizar aspectos que no están disociados e incluso a soslayar aristas que las políticas patrimoniales opacan.

Partiendo de una concepción del patrimonio no como "cosa" o "lugar" sino como proceso cultural selectivo originado con la conformación de los Estados nacionales occidentales dentro de un régimen de propiedad creado en el siglo XIX, dos aspectos me parecen claves para reflexionar sobre las articulaciones entre violencia, derechos humanos y patrimonio indígena en las políticas interculturales. Uno es focalizar en lo que KirshenblattGimblett (2004) ha definido como el carácter metacultural del patrimonio; esto es, en su capacidad para organizar y reflexionar sobre la cultura misma en un sentido amplio. La acentuación evaluativa y afectiva de ciertos valores, conocimientos, historias y experiencias como patrimoniales se funda en $y$, paralelamente, delimita una visión del mundo que dirime la cultura propiamente dicha en cada momento. Por tanto, si el patrimonio surge bajo una matriz cultural occidental, un punto importante es revelar situadamente los implícitos y estándares instituidos o que se pretende instituir en las políticas de patrimonialización que apelan a la interculturalidad acerca de lo que se entiende como "cultural" y aquello que queda amputado o fuera de esas estandarizaciones. El otro aspecto, íntimamente ligado con éste, es examinarlo en su facultad performativa; en aquello que el patrimonio hace. Como plantea Smith (2012), si se comprende al patrimonio como verbo y no como sustantivo, más allá de analizar cómo se construye o qué es el patrimonio, es interesante preguntarse acerca de sus consecuencias y efectos como dispositivo de gobernabilidad. Los regímenes patrimoniales han sido claves en la elaboración de una "estructura de sentimiento" (Williams, 1997), relaciones sociales y moralidades admisibles para la conformación de comunidades imaginadas y la producción de una ciudadanía deseable. Agentes estatales, internacionales y expertos componen la voz autorizada en la producción y diseminación de un sentido del patrimonio legítimo -aunque siempre en tensión y contingente- que funciona como dispositivo de regulación, previsibilidad y control. Pero es dable remarcar, como sostiene Gnecco (2005) que ese sentido es siempre contingente, culturalmente específico e históricamente situado porque está constantemente desplazándose-aunque no espejadamente-con relación a los cuestionamientos y luchas entabladas por sectores alterizados y subalterizados.

Coincido con Rufer (2014), que uno de los desplazamientos 
de los actuales regímenes patrimoniales descansa en haber pasado de una retórica del progreso, que extraía conocimientos u "objetos" del indígena de los márgenes al centro para exhibir una visión de éstos como residuos del pasado, a una retórica multicultural basada en lo que él denominó como "poética del retorno". Este desplazamiento se articula con cambios en las formas de acumulación del capital y en las maneras de dirimir conflictos potencialmente desafiantes tanto a nivel nacional como internacional.

"Ya no se trata, como en la acción decimonónica orquestada por los estados-nación florecientes de exhibir las proezas del orden moderno para educar sobre la ubicuidad del capitalismo en una huida temporal hacia delante, proponiendo al presente como futuro inmediato (Hall, 2007). Se trata más bien de una poética del retorno: permitir que la tradición no esté ya arcaizada en el museo nacional de la capital, sino que lo produzca en la lejanía espacial del pueblo o la aldea: que los que fueron objeto del museo y exhibición se vuelvan sujetos de producción de una mirada y de un orden" (Rufer, 2014: 96-97)

Lo que sigue pretende trazar cuándo, cómo y porqué se fueron encarando ciertas variantes en la agenda política patrimonial en nuestro país (Hall, 1997). Me refiero a cómo se fue concatenando esta poética de preservación con el paradigma de los derechos humanos y que es lo que dicha concatenación hace en el marco de los patrones de gobernanza de una oligarquía que combinó neoliberalismo y conservadurismo.

\section{Pueblos Originarios, patrimonio y derechos humanos}

El entendimiento del patrimonio como derecho deriva de una concepción de la cultura como derecho cultural que tiene entre sus orígenes la Declaración Universal de Derechos Humanos del año 1948 y el Pacto de derechos culturales, sociales y económicos de la ONU establecido en $1966 .^{5}$ Pero su articulación con la diversidad tiene sus antecedentes en los años 1970, en que la noción de cultura en organismos internacionales se amplía para referir al sentido antropológico de "cultura" y al reconocimiento de la "diversidad cultural". Desde entonces, los derechos culturales fueron precisándose y, a partir del siglo XXI, el derecho al patrimonio cultural comienza a enmarcarse dentro de los instrumentos jurídicos internacionales de derechos humanos.

La Declaración de Friburgo -en 2007- ha sido uno

\footnotetext{
${ }^{5}$ La Declaración Universal de Derechos Humanos de 1948 reconoció el derecho a la educación, a participar en la vida cultural de la comunidad, las artes, disfrutar de los beneficios de la ciencia y a proteger a autores de los intereses morales y materiales sobre sus obras científicas, literarias o artísticas. El Pacto Internacional de Derechos Económicos, Sociales y Culturales incluye entre los derechos culturales, la obligación de los Estados de respetar la libertad en la investigación científica y la actividad creadora.
}

de los instrumentos internacionales que reconocieron explícitamente la relación entre el derecho al patrimonio cultural y los derechos humanos (Perez-Prat, 2014; Pabón Cavadid, 2018), y la Declaración de Naciones Unidas sobre los Derechos de los Pueblos Indígenas de ese mismo año hizo lo suyo en materia indígena. Ésta establece que los pueblos y sujetos indígenas tienen derecho a que su cultura no sea destruida y obliga a los Estados a establecer mecanismos para la prevención y resarcimiento de todo acto que tenga por objeto o consecuencia privarlos de sus valores culturales. También consagra su derecho "a mantener, proteger y desarrollar las manifestaciones pasadas, presentes y futuras de sus culturas, como lugares arqueológicos e históricos, objetos, diseños, ceremonias, tecnologías, artes visuales e interpretativas y literaturas" (Artículo 11, 1). Dispone su derecho a desarrollar y enseñar sus tradiciones, costumbres y ceremonias, a mantener y proteger sus lugares religiosos y culturales, acceder a ellos privadamente y a utilizar y controlar sus objetos de culto. Asimismo, incluye la restitución de "bienes culturales, intelectuales, religiosos y espirituales de los que hayan sido privados sin su consentimiento libre, previo e informado o en violación de sus leyes, tradiciones y costumbres; entre ellos a "obtener la repatriación de sus restos humanos" (Cf. artículos 5, 8, 11 y 12). Supone el derecho a participar en la identificación, interpretación, curación y designación del patrimonio cultural que se desea transmitir; fenómeno que, según algunos autores, llevó a romper con aquel enfoque jerárquico que solo circunscribía al Estado la facultad de administrar el patrimonio (Pabón Cavadid, 2018). Declara el derecho a respetar el patrimonio propio, a acceder a otros patrimonios culturales en tanto expresiones de otras culturas y la negativa a promover como patrimonio prácticas culturales que puedan ir contra derechos humanos universales. Además, alienta a que ciertos bienes culturales vinculados ya no con pasados gloriosos ni confortables, sino con experiencias traumáticas relacionadas con la violación de derechos humanos por parte de los Estados, se constituyan como patrimonio a modo de reparación histórica y visibilización de injusticias. Esto es, a conformar lo que varios académicos denominaron como "patrimonios incómodos" o "disonantes" (Macdonald, 2013; Smith, 2011).

Estas y otras declaratorias internacionales sobre la diversidad y el "patrimonio cultural" como derecho humano, provenientes de organismos internacionales -la ONU, UNESCO u otros-surgieron como producto de una serie de luchas indígenas y de otros sectores subordinados por la ampliación de derechos. En el año 2010, la relatora de derechos culturales manifestaba el imperativo ético de defensa de la:

"diversidad cultural, como parte de un compromiso con los derechos humanos y las libertades, en particular los derechos de las personas que pertenecen a minorías y a los pueblos indígenas. [Agregaba que] las obligaciones de los Estados de 
respetar y proteger las libertades, el patrimonio cultural y la diversidad están interrelacionadas, ly que] garantizar el derecho de participar en la vida cultural incluye la obligación de respetar y proteger el patrimonio cultural en todas sus formas y de todos los grupos y comunidades" (Informe de la Experta independiente en la esfera de los derechos culturales, Sra. Farida Shaheed, presentado de conformidad con la resolución 10/23 del Consejo de Derechos Humanos 2010: 11-12).

Ahora bien, un punto a destacar es que la inclusión de estos derechos como derechos humanos dentro de estos organismos internacionales se ha fundamentado en la idea de que el impulso al patrimonio y los derechos culturales facilitan el diálogo y resultan indispensables para alcanzar la convivencia pacífica, la seguridad o, lo que es lo mismo, la resolución y prevención de conflictos (Cf. Serie sobre Diversidad Cultural 1, UNESCO, 2002 e informe relatora Farida Shaheed, 2010).

En Argentina, junto a la idea del patrimonio y la diversidad como recurso, la lectura de la cultura y el patrimonio como derecho humano adquirió un espacio de discusión y centralidad durante la gestión del gobierno kirchnerista6 ${ }^{6}$ (2003-2015). Lo hizo sobre todo en relación a las experiencias de violación de derechos humanos entablada por el terrorismo de Estado de la última dictadura militar, que constituyó centralmente la política de derechos humanos de dicha gestión. Sin embargo, la idea de pensar la política en términos de derechos desbordó esa esfera. Las políticas del gobierno kirchnerista fueron pasando de la acción focalizada -que prevalecía durante el neoliberalismo- a su alcance universal, y de la idea de sus destinatarios como beneficiarios pasivos a su conceptualización como sujetos activos de derecho. En ese marco, la noción de derecho permeó otras dimensiones, como por ejemplo programas y anteproyectos de leyes de cultura ${ }^{7}$ e incluso políticas indigenistas. Desde ya, en el caso indígena este desplazamiento hacia la noción de sujetos de derecho no era novedoso. Los derechos indígenas se encontraban legislados desde la reapertura democrática y con la profundización de la política económica neoliberal de los años 1990 se habían proclamado los derechos indígenas

\footnotetext{
${ }^{6}$ Los gobiernos de Néstor Kirchner y Cristina Fernández de Kirchner han sido localmente denominados bajo el apodo "kirchnerismo"/ "kirchnerista".

${ }^{7}$ Esta idea de los derechos culturales se materializa en la discusión del anteproyecto de la "Ley Federal de las Culturas" elaborado en el año 2014. Este anteproyecto propone reconocer a las culturas como un derecho humano inalienable que debe ser garantizado por el Estado. El plural responde a la necesidad de reconocer la diversidad cultural existente en el país en términos de género, étnico, lingüístico, etc. Si bien no se constituyó en ley, me interesa marcar que el proyecto reconoce como preexistentes y existentes a los pueblos originarios y fue elaborado para contrarrestar el carácter mercantil que adquieren las producciones culturales en contextos de neoliberalismo y restauración conservadora; y promover una propuesta emancipadora de soberanía cultural.
}

en el plano constitucional y al menos a nivel formal. Pero entre 2003 a 2015 adquirió nuevos ribetes en tanto se impulsaba bajo otro tipo de contrato de ciudadanía inscripto en un proyecto de signo nacional-popular (Briones, 2015; Soria, 2019), que en su discurso criticaba el neoliberalismo, exhortaba la unificación latinoamericana, reivindicaba imágenes de una nación mestiza incluyendo en su historia -aunque de manera racializada, según Briones (2015) - el aporte de los pueblos originarios en su constitución y sostenía a estos derechos como un acto de reparación histórica, "inclusión" y justicia. Sin embargo, paralelamente mantenía ciertos límites sobre esos derechos. Entre ellos, cabe mencionar experiencias de violencia no escuchadas que se desplegaban en algunas provincias, como fue el caso de la represión del Estado provincial de Formosa ante el reclamo territorial de la comunidad Qom Potae Napocna Navogoh liderada por Félix Díaz. ${ }^{8}$

De manera que, al calor de las políticas del kirchnerismo, las demandas de los pueblos indígenas fueron ampliándose y definiéndose cada vez más apelando al lenguaje de los derechos e incluso desbordando aquellos instituidos (Soria, 2019). En los últimos años, junto al reclamo indígena por derechos territoriales que tienen larga data y el derecho a la identidad, emergieron otros íntimamente articulados con éste. Me refiero al derecho a garantizar la participación indígena en los temas que los involucra, reconocer los derechos de propiedad intelectual, la biodiversidad y los derechos consuetudinarios, establecer una educación intercultural bilingüe y el derecho a disponer de la pertenencia y/o gestión de lo que se clasificó como "patrimonio arqueológico" del Estado nacional y provincial -en especial, de los restos humanos que se reclaman como sus antepasados aunque también de espacios sagrados y otras manifestaciones de la vida cotidiana o sagrada que han sido apropiados por museos y definidos como objeto de estudio por los académicos. Estas demandas, vinculadas con históricas experiencias de despojo, discriminación y violencia física, moral y epistémica están atravesadas por el reclamo a la autodefinición y autodeterminación como pueblo. A la par, junto a estas demandas, los indígenas fueron ampliando recuperaciones territoriales sobre espacios que les fueron confiscados -tal como ya lo señalé- y reclamando sobre territorios que vienen siendo avasallados por emprendimientos neoextractivistas o de otra índole.

La nueva administración de gobierno de Macri no eliminó en sus proposiciones enunciativas la noción de "derechos". Más bien operó con el paradigma de los derechos humanos imprimiéndole una serie de torsiones. Oficializó un reclamo indígena y traspasó la dependencia

\footnotetext{
8 En noviembre de 2010 la comunidad qom Potae Napocna Navogoh es reprimida por las fuerzas policiales de Formosa cuando realiza un corte de ruta demandando por su territorio. En dicha represión muere un integrante qom y un representante de la fuerza policial. A partir de entonces, miembros de la comunidad deciden trasladarse a Buenos Aires y hacer un acampe hasta ser escuchados por el gobierno nacional. Para mayor detalle sobre lo sucedido léase Soria (2019).
} 
del Instituto de Asuntos Indígenas de la Secretaría de Políticas Sociales y Desarrollo Humano del Ministerio de Desarrollo Social, donde había sido ubicado por el gobierno anterior, a su actuación dentro del Ministerio de Justicia y Derechos Humanos. Este traspaso formó parte de una ampliación de la acción de la Secretaría de Derechos Humanos. Hasta la fecha, la política en derechos humanos había estado exclusivamente asociada a experiencias de violación de derechos humanos desplegadas durante la última dictadura militar. El cambio de gobierno albergó como parte de la agenda a colectivos que con anterioridad no estaban incluidos: afrodescendientes, romaníes, diversidad de género y pueblos originarios. Renombró el área como "Secretaría de Derechos Humanos y Pluralismo Cultural" y, elaboró el "Primer Plan Nacional de Acción en Derechos Humanos (2017-2020)" -PNADH 2017-2020- que incluyó, entre otros colectivos, a los pueblos indígenas.

El PNADH 2017-2020 se presentó como "una herramienta que apunta a fortalecer la promoción y protección de los derechos humanos por parte del Estado, fomentar una sociedad pacífica y contribuir al bienestar de las personas en situación de mayor vulnerabilidad" (https:// www.argentina.gob.ar/noticias/los-derechos-humanosson-politica-de-estado). Mientras la inscripción de la política indigenista y de aquellos otros colectivos sociales dentro de la Secretaría de Derechos Humanos se alineaba al paradigma internacional sobre diversidad cultural y derechos humanos que el gobierno estaba interesado en impulsar; hacía parte de dos efectos más. Por un lado, de una serie de medidas a través de las cuales se quiso restar poder a los organismos de derechos humanos y la lucha por la memoria, la verdad y la justicia. ${ }^{9}$ Paralelamente, se vinculaba con un interés por diferenciarse de la política en derechos humanos llevada adelante por el gobierno anterior: ${ }^{10}$

“los organismos internacionales vienen pidiendo la puesta en marcha de este plan y sin embargo hasta ahora la Argentina no había dado una respuesta a este pedido". "Hoy elegimos cambiar, estamos integrados en el mundo y estamos decididos a cumplir nuestros compromisos", aseveró [el presidente Mauricio Macri]. El mandatario precisó

\footnotetext{
9 Entre esas medidas, cabe recordar recortes presupuestarios en el área, el cierre del área de derechos humanos del Banco Central -que investigaba el papel de este banco y de las corporaciones en la dictadura además de políticas de género en el sistema financiero y fenómenos actuales como trata de personas y lavado de activos vinculados con ello-, la cantidad de despidos en otras áreas de derechos humanos de otros ministerios que producían investigaciones relevantes para documentar en los juicios por los delitos de lesa humanidad, etcétera.

10 Antes de asumir como presidente, Macri había cuestionado públicamente a la política de derechos humanos y a los propios organismos como parte de un "curro" o "abuso". Criticaba la asociación de varios organismos con el kirchnerismo y la circunscripción de los derechos humanos a la violencia institucional perpetrada por la dictadura. Pero además, consideraba que la lucha de estos organismos formaba parte de una venganza.
}

que se trata de "243 compromisos prioritarios, una política de Estado que forma parte de los 100 objetivos prioritarios de este gobierno, en consonancia con los tres principales ejes de nuestra gestión: bajar la pobreza, luchar contra el narcotráfico y unir a los argentinos" (12/12/2017. Disponible en https://www.ambito.com/gobiernolanzo-plan-ddhh-las-politicas-memoria-verdady-justicia-estan-garantizadas-n4006294. El subrayado pertenece al original)

A pesar de que en varias oportunidades el presidente y algunos funcionarios han asociado públicamente al argentino con una identidad blanca y europea y celebrado la homogeneidad lingüística en torno al "español", el traspase respondía a una impronta política que ya desde un inicio el nuevo gobierno se propuso instalar en el imaginario social. Esto es, su interés por exhibir vocación de "diálogo" en todos los niveles de la sociedad para desterrar la "confrontación" y "recuperar el orden". En especial el diálogo con quienes el gobierno anterior había tenido varios conflictos que habían traspasado a la esfera pública, como fue el caso de los pueblos originarios. ${ }^{11} \mathrm{Y}$ es que si bien el kirchnerismo inicialmente atendió a muchas de sus demandas, ${ }^{12}$ los límites ocurridos sobre algunas de ellas fueron generando confrontaciones que se hicieron públicamente visibles en el 2013 (Briones, 2015; Soria, 2019). En esa dirección, la nueva gestión gubernamental comunicó reiteradamente que propiciaría la participación, la "unión de los argentinos" y el diálogo aun entre sectores no equivalentes e incluso con intereses diametralmente opuestos. ${ }^{13}$ La reunión del presidente en los inicios de su mandato con Félix Díaz y Relmu Ñanku -el primero,

\footnotetext{
${ }^{11}$ Como señala Soria (2019) "el kirchnerismo impactó en subjetividades indígenas y convocó adhesiones a partir de la centralidad que otorgó al bienestar de las mayorías y al discurso de los derechos (...) [pero] las reinscripciones de etnicidad que permitieron que demandas indígenas fueran parte de lo "nacional y popular" abrieron un campo fértil para que determinados sujetos articularan sus propias memorias de injusticia, desafiando los límites imaginables de la inclusión" (Soria, 2019: 209).

12 En el año 2004 se desarrollan foros regionales y el Foro Nacional de "Derecho de los Pueblos Indígenas en la Política Pública" con el objeto de discutir demandas y propuestas de políticas al Estado. Se crea el "Consejo de Participación Indígena" en el INAI, como forma de cumplir con la representación indígena que rige en la Ley 23302. En el 2006, se crea la Dirección de Pueblos Originarios y Recursos Naturales dentro de la Secretaría de Ambiente y Desarrollo Sustentable bajo la dirección de dos referentes indígenas. En el 2006 se sanciona la Ley Nacional de Educación 26206, que incorpora como modalidad educativa la educación intercultural bilingüe; la Ley 26160 de emergencia en materia posesión y propiedad de las tierras que tradicionalmente ocupan las comunidades indígenas del país. En 2009, la Ley 26522 de Servicios de Comunicación Audiovisual promueve el derecho a la comunicación con identidad. En el 2010, durante el festejo del Bicentenario, aunque representados en el pasado, se incorpora dentro de la puesta en escena de la historia nacional a los pueblos indígenas. En ese mismo año se redefine el 12 de Octubre "Día de la diversidad" en lugar de "día de la raza". En 2011 se crea la Coordinadora de Comunicación Audiovisual Indígena Argentina. En el 2014 se inaugura el salón Pueblos Originarios en la Casa Rosada, en lo que antes se había denominado sala Cristóbal Colón.

13 Valga como ejemplo el encuentro con defensores de los militares genocidas por el Secretario de Derechos Humanos.
} 
referente qom de Formosa y, la segunda, una referente mapuche de Neuquén- que habían tenido fuertes conflictos con el gobierno anterior, y la creación por Decreto presidencial del Consejo Consultivo y Participativo Indígena de la República Argentina ${ }^{14}$ demandado por aquel referente (Decreto 672/2016), apuntaban a mostrar la escucha, la apertura a la participación y la iniciativa de elaborar una agenda común en la que, en palabras del presidente Macri, "el aporte de cada uno cuente, pese, sea reconocido" (https://www.telam.com.ar/multimedia/ video/12100-macri-recibio-a-representantes-de-mas-de30-etnias-de-pueblos-originarios/).

\section{Incomodidades y encuadramientos: Del patrimonio como derecho humano al conocimiento ancestral como insurgencia}

Como señalé en la introducción, el gobierno nacional de Macri hizo de la difusión visual de la gestión de cada institución del Estado a través de medios tecnológicos una política de gobierno en sí misma. Las agencias estatales se vieron "obligadas" a divulgar de manera continua las acciones desarrolladas en cada institución a través de sus páginas web, la apertura de redes como Facebook y/o el envío de correos electrónicos a los ciudadanos. Con el cambio de lugar en el organigrama estatal, el Instituto de Asuntos Indígenas configuró su página web adecuando sus políticas bajo el paraguas del "derecho" y los desagregó en: el derecho al respeto por su identidad cultural, por sus valores, prácticas e instituciones, por el acceso a la tierra y el territorio, a la educación intercultural bilingüe, a la justicia, al desarrollo con identidad, a la consulta previa y participación, al respeto a sus saberes y conocimientos ancestrales, a la comunicación con identidad, a la no discriminación y a la salud intercultural. Lo hizo traduciéndolo en cuatro idiomas indígenas, como un primer gesto de ese reconocimiento de derecho a la diversidad indígena, y delineó su rol institucional como impulsor de la participación de las comunidades en el diseño y gestión de políticas públicas según "sus formas de organización tradicional y sus valores".

\footnotetext{
${ }^{14}$ Según el artículo 3 del Decreto, el Consejo Consultivo tiene como funciones: "a. Impulsar la reforma de la Ley $N^{\circ} 23302$, adecuándola a los estándares internacionales; proponer un proyecto de reglamentación del derecho a la consulta previa, libre e informada, conforme a lo establecido por el Convenio 169 de la OIT aprobado por la Ley Nº 24071 y un proyecto de reglamentación de la propiedad comunitaria indígena; b. Fortalecer la identidad sociocultural y el autogobierno; $c$. Impulsar el relevamiento y ordenamiento del territorio para la efectiva posesión de las tierras por las comunidades; d. Impulsar, proponer al Estado nacional participando: en el proceso de toma de decisión para la implementación de los programas, planes y proyectos para la Población Indígena, de educación, salud, género, juventud, protección de niños y niñas, tercera edad, ancianos, discapacidad y asistencia a víctima; e. Promover la redefinición de las diferentes áreas relativas a políticas hacia Pueblos Indígenas en los diferentes Ministerios y organismos públicos del Estado nacional con el objeto de garantizar la participación indígena; f. Impulsar medidas para la protección, defensa y desarrollo de los recursos naturales, genéticos y de biodiversidad de los territorios, los conocimientos y saberes ancestrales, y cualquier otro tema que revista importancia para los Pueblos y/o Comunidades Indígenas" (Decreto 672/2016).
}

En el año 2017, en pleno conflicto y represión a los mapuche en Patagonia, movilización pública por estos hechos y debate en torno a la renovación de la Ley de relevamiento territorial indígena, el INAI cambia su presidente. Comienza a ser dirigido por Jimena Pshatakis, una politóloga que había sido Directora Nacional de Protección de Derechos y Resolución de Conflictos de la Secretaría de Derechos Humanos y Pluralismo Cultural de la Nación. La elección de este perfil como presidenta de la institución resulta significativa.

Desde entonces, la elección de discursos e imágenes propagados por este Instituto deben leerse en el marco de ciertos aspectos que quisiera destacar respecto del cúmulo de eventos y enunciaciones desplegadas en ese contexto. El primero de ellos se relaciona con la asociación de la pu lof en Resistencia Cushamen con una organización denominada Resistencia Ancestral Mapuche -más conocida por sus siglas como RAM- que fue vinculada con el terrorismo. Unas pocas imágenes repetidas una y otra vez en los medios de comunicación hegemónicos fueron desplegadas para confirmar esta vinculación y justificar el accionar represivo tanto por parte del ejecutivo -altos funcionarios del Ministerio de Seguridad, el presidente y la vicepresidenta- como de los medios oficialistas. ${ }^{15}$ Pero los términos también hicieron otros ecos, más aun en su relación con la noción de "desaparición forzada" con la que se caratuló la desaparición -luego de dos meses encontrado muerto en el río- de Santiago Maldonado y la represión y matanza de Rafael Nahuel tras la recuperación territorial que Ilevó adelante la comunidad Lafken Winkul Mapu en Lago Mascardi. Esos términos y acciones trajeron a la memoria el terrorismo de Estado de la última dictadura militar y la violencia institucional ejercida en períodos democráticos. También la articulación de las protestas indígenas con derechos indígenas no reconocidos, históricamente postergados. Frente a estas resonancias, lo ocurrido fue leído con diferentes acentos, según sectores e intereses sociales opuestos, a la luz de la díada "guerra-paz". Altos funcionarios declaraban que las recuperaciones territoriales de ambas comunidades eran hechos de violencia terrorista. En los medios de comunicación aparecían títulos como "la guerra por la tierra". Los parlamentarios que consensuaron finalmente renovar la ley de relevamiento territorial, argumentaban desde posiciones opuestas - desde visiones progresistas a otras conservadoras de derecha-su decisión de aprobarla apelando a la necesidad de reforzar la paz social. En correlación con esto y como consecuencia de la dimensión que alcanzó el debate sobre estos hechos de violencia en la esfera política y social, a un mes de la matanza de Rafael Nahuel, en diciembre de 2017, la Secretaría de Derechos Humanos y Pluralismo Cultural presenta su Plan

\footnotetext{
15 Imágenes de los mapuche con la cara totalmente tapada, de herramientas de trabajo rural que se definían como "armas", de una multitud de gendarmes ingresando al campo, del corte de ruta con gomas incendiadas, etcétera.
} 
Nacional de Acción en Derechos Humanos 2017-2020 de carácter transversal y federal, que alcanza a los pueblos indígenas. En la presentación, la presidenta del INAI ubica la violencia institucional en un pasado previo al gobierno actual, destaca al plan como la forma en que éste resuelve esa "histórica" violación de sus derechos, encapsula la violencia institucional en un pasado muy previo y ubica a la institución en el lugar de la paz dentro de aquella díada:

"La invisibilización, marginación y violencia que sufrieron nuestros pueblos originarios a través de siglos, produjeron una violación sistémica de sus derechos y una expansión de sus problemáticas que hoy abarcan desde acceso a la salud, pasando por la educación, el trabajo, la vivienda, hasta el respeto a su identidad cultural (...) La respuesta (...) es un plan. Un plan nacional que parta de un diagnóstico certero, que fije prioridades y que avance para conseguir metas sostenibles a corto, mediano y largo plazo. Y, por supuesto, que incluya la participación de los pueblos y el compromiso de todos los sectores de nuestra sociedad. Así nacieron las Metas de la política nacional de pueblos originarios del INAI, las cuales son parte del Plan Nacional de Acción en Derechos Humanos de la Secretaría de Derechos Humanos y Pluralismo Cultural (...) El desafío es enorme, pero tenemos conciencia sobre la necesidad imperiosa de llevarlo a cabo. Porque soñamos con una argentina diversa, respetuosa, digna y en paz" (https://www.telam.com. ar/notas/201801/242367-pueblos-originarios-plannacional-opinion-jimena-psathakis.html).

Desde entonces a esta parte, el portal de la institución omitió acuñar el término violencia, con excepción en algunos casos puntuales de la violencia de género, y silenció cualquier situación de conflicto, en especial los sucesos ocurridos en ambas comunidades mapuches de Patagonia. ${ }^{16}$ Contrariamente, divulgó no tanto acciones concretas vinculadas con políticas de orden territorial, de educación, salud o de infraestructura necesarias para mejorar las condiciones de vida de estos pueblos sino encuentros y convenios de algo que se iba a desarrollar a futuro, mesas de diálogo que recién se iniciaban, visitas a comunidades, elecciones de representantes indígenas, conversatorios sobre "Cultura de Paz, Derechos Humanos y pueblos indígenas", fechas conmemorativas o bien talleres con perspectiva de género y algunas acciones que las definió como acciones de fortalecimiento de derechos

\footnotetext{
16 Estos silenciamientos se replicaron en las entrevistas otorgadas por la presidenta del INAI a los medios de comunicación. Para dar un ejemplo, en una entrevista mantenida en la TV pública, Pshatakis no mencionó a Santiago Maldonado ni las represiones desplegadas en las comunidades mapuche en Patagonia. Resaltó, sí, la existencia de un plan institucional del INAI basado en el otorgamiento de derechos que ella consideraba básicos a la población indígena del país como acceder a la salud, a la educación y en el caso del norte por ejemplo, al documento nacional de identidad. También mencionó la necesidad de prorrogar la ley 26160 y resolver la situación territorial indígena, aunque como mencionaré en el texto, esto último sigue todavía sin resolución.
}

indígenas; entre ellos, el derecho a la participación, a la documentación nacional (DNI), a la perspectiva de género $y$, particularmente, al patrimonio. Una primera lectura analítica obvia es que la acción política en materia indígena fue por demás escasa en esos cuatro años. En especial, poco se avanzó en el relevamiento territorial, la ley de propiedad comunitaria indígena no fue discutida en el Congreso Nacional y hubo muchas críticas respecto al escaso presupuesto otorgado al Instituto. Pero me interesa ir más allá de este señalamiento para precisar, en todo caso, la importancia política que tenía la sobreexhibición de estos derechos culturales entendidos como derechos humanos, basados en normativas nacionales e internacionales.

En su mayoría, las noticias informaban sobre otorgamientos de Documentos de Identidad, conversatorios o mesas de mujeres indígenas que se capacitaban en torno al derecho de la mujer indígena, la realización de talleres sobre derechos indígenas o de elecciones de representantes indígenas y, en particular, se asentaban sobre proyectos que anclan en la memoria y el patrimonio indígena, sean entendidos como recursos para su comercialización o como fuente de preservación. Poco descriptivas en términos de contenido, las noticias indicaban la provincia, comunidad y funcionarios que participaban de los encuentros; se acompañaban de imágenes que los exhibía distribuidos alrededor de una gran mesa o en forma de círculo en los espacios donde viven las comunidades y señalaban los convenios, leyes constitucionales y otras normativas a las que se avenían estas acciones. Aspectos, todo ellos relevantes si se tiene en cuenta la crítica que atravesaba el gobierno en ese momento de estar quebrantando el Estado de derecho.

Dentro de los programas vinculados con el patrimonio, uno de los proyectos que se encaró en la institución fue la creación de un Archivo Intercultural de Historia Oral. Este Archivo incluiría la preservación de entrevistas audiovisuales a indígenas sobre tradiciones, vivencias, cuentos, prácticas medicinales, alimentos, costumbres, migraciones, fábulas, leyendas, experiencias vividas y conocimientos ancestrales, dentro del Archivo Nacional de la Memoria. Los otros dos programas relativos al patrimonio preceden a este gobierno. Uno está vinculado con el fomento al artesanado y otros saberes y prácticas indígenas para su comercialización y puesta en exhibición turística dentro de lo que ha sido denominado desde hace ya varios años como "Marca País". Como parte de un nuevo modo de dominación, las políticas neoliberales han procurado socializar como valor positivo una cultura del emprendedurismo vis a vis del sujeto emprendedor basada en el (des)conocimiento de la estructura económica desigual sobre la que se asienta (Commaroff y Commaroff, 2011). La política indigenista no quedó ajena a ello sino a la inversa: sus producciones, prácticas culturales y las mismas comunidades indígenas se vieron alcanzadas por ésta, 
incluso durante el gobierno kirchnerista. La incorporación a este programa ha supuesto la adecuación a aquello que el programa ha establecido. Las noticias difundían encuentros y capacitaciones en torno a esto, visualizando la inclusión de esos conocimientos indígenas y mostrando al Instituto como facilitador de trámites burocráticos, administrativos y promotor de la realización de talleres en articulación con otras instituciones. El otro programa consiste en la restitución de restos humanos indígenas. Esta política de restitución formó parte de una demanda indígena que también había incorporado la gestión de gobierno anterior. Varias comunidades indígenas habían reclamado el derecho a enterrar a sus ancestros y disponer de entornos, producciones culturales y sagradas que han sido apropiadas, coleccionadas, exhibidas o depositadas en museos por el Estado bajo una lógica patrimonial, como "ruinas" o "restos" de su propiedad. Los indígenas han cuestionado esta "apropiación" como parte de una historia de despojos, avasallamientos, fragmentaciones y violación de sus saberes, territorialidades, cosmovisiones, ancestralidades y derechos sin solución de continuidad por parte de un Estado que le ha impedido fijar sentidos sobre sí mismos y decidir sobre lo propio, incluso sobre aquello que no quieren decir ni exhibir (Crespo, 2016). La creación de este programa basaba su fundamento en la reparación histórica, la justicia y la restitución de derechos.

Ninguna de estas políticas patrimoniales presupone la erogación de gran presupuesto. Sin ir más lejos, durante el 2018 los subsidios vinculados con la capacitación o fomento de prácticas y saberes indígenas -artesanías, música, talabartería, etc.- fue propiciado no como parte de un programa con continuidad en el Instituto sino a través de un concurso anual del Fondo Nacional de las Artes. Además, tal como están expresadas, tampoco estas políticas vinculadas con el patrimonio cultural chocaban con intereses económicos, ni ponían en riesgo políticas neoextractivistas y territoriales que se han querido profundizar. Pero su relevancia y anuencia radicaba en aquello que capitalizaban estas exhibiciones de interculturalidad fuertemente ancladas en acciones patrimoniales y derechos humanos, tanto a través de lo que volvían objeto de exposición y conmemoración como de lo que borraban, negaban y ausentaban.

Reygadas (2014) plantea que la lectura del patrimonio, la memoria y el desarrollo de la identidad étnica y cultural como derechos forman parte de la tercera generación de derechos culturales. Reconociendo que estos derechos en los que se inscribe el patrimonio y las políticas de interculturalidad conforman un signo de época, sería un error sostener que vehiculizan los mismos contenidos y efectos en cada contexto en el que se reinscriben. En Argentina, en el marco de políticas neoliberales y conservadoras que han precarizado las condiciones de existencia y han hecho uso y celebrado la violencia institucional estatal, me parece importante advertir en esta profusión de noticias que enmarcaban las políticas patrimoniales interculturales del INAI al menos tres efectos o impresiones. Sabemos que aun las restituciones de restos humanos que han sido coleccionados y/o exhibidos en museos y que parecerían vincularse con una temporalidad más lejana no lo están, y generan tensiones tanto interinstitucionales como desacuerdos con comunidades indígenas demandantes. También que muchos de estos reclamos se articulan con demandas territoriales y de autodeterminación. $\mathrm{E}$, incluso, que el propio lenguaje "patrimonial" asentado en un paradigma epistémico occidental supone limitaciones y encuadramientos -tal como señalé en anteriores escritosy viene siendo objetado por muchos indígenas cuando se trata de restituir a sus ancestros o espacios que se conciben sagrados. El INAI, a la inversa, comunicaba públicamente todas estas memorias, cuerpos, espacios y saberes como resultado de un "diálogo intercultural", organizándolos como patrimonios dados, omitiendo debatir la limitación del carácter universalista desde el que nomina, clasifica y ordena racionalidades, saberes, experiencias y prácticas indígenas dentro de una visión del patrimonio como derecho humano y sin entrecruzarlos con demandas económicas y políticas. Las imágenes exhibidas de reuniones en círculo o alrededor de una mesa entre funcionarios de distintos organismos estatales e indígenas retratadas mayormente en los espacios territoriales indígenas, apuntaban de hecho a plasmar la idea de "espacios de encuentro entre iguales" y de un Estado presente que se acercaba y escuchaba a las comunidades. Sin duda, un primer efecto de estas políticas patrimoniales indígenas ha sido mostrar al gobierno bajo aquella "vocación de diálogo y unidad" que éste quiso imprimir en el imaginario a su gestión. Pero sobre todo, a partir del año 2017, en el que se estaba discutiendo la necesidad de la "paz social" y se interpelaba al gobierno por la ausencia de un Estado de derecho, estas acciones patrimoniales importaron por su segundo efecto. Quiero decir, porque a través de ellas se podía performar esa "convivencia en paz", reclamada por amplios sectores de la sociedad, y se procuraba probar que las políticas estaban enmarcadas en los derechos humanos. Tanto las noticias sobre las restituciones de restos humanos indígenas, que retrataban una violencia estatal que aparecía detenida en el pasado y la restitución del derecho, como la difusión de fotos del Archivo Nacional de la Memoria como espacio de acogida del Archivo intercultural de Historia Oral, aportaban a alimentar la idea de que las acciones gubernamentales en materia indígena se adecuaban a los derechos humanos.

Hasta aquí, cabe preguntarse si estamos acaso frente a patrones de gobernanza contradictorios en los que, por un lado, las políticas indigenistas, y en particular patrimoniales, se promueven como derechos humanos $y$, por otro, se entablan ejercicios de violencia extrema frente reclamos de derechos; o bien, si como señalan Barros y Quintana (2019), estamos frente a dos caras de una misma matriz de gobernabilidad cuyo ejercicio 
de dominación opera haciendo comulgar prácticas políticas que sólo en apariencia resultan antitéticas. La respuesta me lleva al tercer efecto que entiendo produce el patrimonio indígena como derecho humano en contextos de violencia institucional. Aun acordando con Macdonald (2013) que, en la medida en que el patrimonio se percibe como algo pasado puede ser visto como menos contencioso y en potencia más fácil de manejar por el Estado, los eventos sucedidos en estos años habilitan a preguntarse ¿cuándo y por qué ciertos conocimientos, formas de pensarse y prácticas culturales ancestrales dejan de ser leídos por el Estado en clave "patrimonial" y se visualizan como fuerza insurgente? ¿dónde empieza y termina el derecho a tener derechos?

A lo largo de estos años, el derecho a la diversidad cultural y la interculturalidad como fuente de reclamo subalterno derivó en un concepto hegemónico en el que deben dirimirse las demandas y establecerse los acuerdos en materia indígena. Pero aun cuando nadie podría negar su relevancia, esos derechos una vez instituidos van mostrando sus bordes y esos bordes se van complejizando a partir de interpelaciones que van corriéndose de lo estrictamente reconocido. Volvamos a la recuperación territorial Ilevada adelante por la lof Lafken Winkul en cercanía al Lago Mascardi en Patagonia y repongamos las imágenes faltantes y aquello que no fue dicho o puesto en circulación en las redes ni en la página de la institución. Me refiero al lugar que, como señalaron Kropf (comunicación radial en Bariloche, 2017) y Ramos (2018), el conocimiento ancestral, concebirse como parte del territorio y las ceremonias que intervienen en la preparación para el aprendizaje de ser machi-una figura mapuche que cumple roles espirituales y sociales, con conocimiento para curar dolencias físicas y aquellas derivadas de la acción de fuerzas espirituales- tuvo en esa recuperación territorial. En efecto, como destacaron ambas antropólogas, en base a una noción de territorio que excede aspectos de índole económico para relacionarse con la espiritualidad y filosofía mapuche, miembros de esa lof que residían en los barrios muy pobres y periféricos en Bariloche, explicaron la recuperación de ese espacio territorial como producto de la necesidad de realizar allí las ceremonias para "levantar" a la machi de su comunidad. Afirmaban que las fuerzas de ese espacio los había llamado a terminar ahí su aprendizaje (Ramos, 2018). En estos últimos años, varios mapuche sostienen públicamente la existencia de relaciones entre las fuerzas del territorio y los humanos tanto como de la interacción entre los antepasados y el mundo de los "vivos" y las consecuencias que trae la ruptura de estas relaciones. La respuesta estatal a dicha recuperación territorial fue la represión e involucró el asesinato de Rafael Nahuel sobre el que hasta hoy no termina de dictarse justicia. Los funcionarios lo justificaron propagando la idea de que se trataba de indígenas violentos, terroristas, que atemorizaban a los ciudadanos y hacían peligrar el orden social. Algunos periodistas acompañaron esta interpretación. Observaban al hecho como una "violenta toma de tierras" por parte incluso de "oportunistas" que declamaban como justificativo una supuesta sacralidad u otra forma de pensarse de la que periodistas y funcionarios se mofaban. Otros periodistas los concibieron como "una pandilla rural que tiene una verborragia revolucionaria bastante primitiva" (https:// www.perfil.com/noticias/politica/el-papelon-de-michettiante-tenembaum-por-los-mapuches-tenian-lanzas.phtml), y finalmente, otros cuestionaron el accionar represivo del gobierno como parte de un plan sistemático antimapuche.

Sin embargo, aquello que ninguna de las exposiciones públicas ponía en discusión es por qué si el conocimiento y prácticas ancestrales en tanto oficialmente definidos como patrimonio intangible se entienden como un derecho humano, en ciertas coyunturas se comprende como terrorista y desafiante, justificando un accionar que viola derechos humanos reconocidos. En enero de 2018, el Ministro de Justicia Germán Garavano señalaba:

"(...) todo el trabajo que viene realizando el INAI y la Secretaría de Derechos humanos en materia de trabajo con los pueblos originarios ya no [es] desde una perspectiva asistencialista sino desde una perspectiva de derechos y ejercicios de derechos. Esto va en línea con todas las acciones que se están haciendo más allá del relevamiento [territorial] que tienen que ver con acceso a justicia, con acceso a la salud, acceso a documentación y al reconocimiento (...) Y el otro tema que también marcamos claramente es que la vía para solucionar estos problemas -en Argentina el Estado tiene claramente una deuda con los pueblos originarioses el diálogo, es el cumplimiento de la ley y no los hechos de violencia que hemos vivido en el último tiempo" (http://politica3d.com.ar/actualidad/ casa-rosada-el-ministro-de-justicia-germangaravano-y-el-secretario-de-ddhh-claudio-avrujse-reunieron-con-representantes-de-neuquen-rionegro-y-chubut/12 de enero 2018)

Si el patrimonio es un proceso que comunica y actualiza selectivamente prácticas, experiencias, moralidades, emociones, valores configurando sentido de pertenencia, redes de relaciones y jerarquías políticas y sociales, ¿cuál es entonces el tercer efecto que produce esta puesta en escena de una interculturalidad que aprecia ciertos conocimientos bajo la lógica del patrimonio instituido como derecho humano? No cabe duda, como señala Marisol de la Cadena (De la Cadena, Risor y Feldman, 2018), que bajo estos términos patrimoniales nos encontramos frente a la violencia de una hegemonía que vuelve inexistente aquello que no conoce. Pero me importa señalar, en todo caso, que la producción de inexistencias mediante la sobre-exhibición de aquellos patrimonios restituidos y reconocidos como derechos humanos indígenas lavados de sus historias, tensiones y despojos, y escenificados en montajes de espacios de 
encuentros interculturales o diálogos en convivencia pacífica enmarcadas en derechos humanos, permiten, además, en ciertos contextos, singularizar la represión de las fuerzas de seguridad como eventos "aislados" por parte de poderes que, aun sin decirlo en voz alta, consideran que "el diálogo" no habilita la posibilidad ni el derecho al disenso. Más aun, esa política pendular que se desplaza de una definición del indígena como sujeto de derecho a otra que lo define como amenaza, es parte de un patrón de gobernanza que excluye y quiere evitar que el lenguaje de una diversidad cultural disidente, que opera fuera de los marcos hegemónicos establecidos, se propague a otros procesos de recuperación territorial alterando alteridades reconocidas. Alteridades desafiantes que en su accionar interpelan no sólo a los intereses del capital sino a las propias bases culturales, epistémicas y lógicas coloniales de un ordenamiento fundamentado en propiciar una interculturalidad basada en derechos humanos.

\section{Consideraciones finales}

Como sugiere Sousa Santos, el lenguaje de los derechos humanos habilita y puede enlazarse con violencias evaluadas y manejadas de acuerdo con estándares dobles (2002: 67). En un gobierno neoliberal y conservador que precarizó condiciones de vida de sectores vulnerados, profundizó políticas neoextractivistas, reprimió el disenso y celebró la "mano dura", la noción de "derechos humanos" como política de Estado circuló repetidamente como un continente normativo sin contenido. Es decir, una etiqueta opaca, vaciada, por un lado, de sus historias de discusión y lucha que le dieron sentido en nuestro país; y por otro lado, de las trayectorias, epistemes y concepciones del mundo de los distintos colectivos que se ha pretendido abarcar.

Aun cuando, como decía en la introducción, el lenguaje de la represión, judicialización y discriminación estatal hacia el mapuche fue particularmente significativa en estos últimos cuatro años; la incorporación de la diversidad indígena en el plano de las políticas públicas de Derechos Humanos fue, si se quiere, novedosa y su banalización, potente. Como eje de políticas indigenistas "interculturales" dentro del régimen actual neoliberal y conservador propulsado por una oligarquía en Argentina, las discusiones ancladas en la noción de "cultura" y "patrimonio" como derecho humano, delimitan la "alteridad", definen, estandarizan y vuelven previsible lo "particular" y encuadran y regulan convivencias deseables. En líneas generales, las políticas interculturales recientes han tendido a entender a los pueblos originarios a partir de sus diferencias puras con Occidente y a desconocer sus trayectorias e intersecciones con experiencias de clase, de género, generacionales, etcétera (Crespo, 2016). Pero si lo que se suscribe es esta "poética del retorno" (Rufer, 2014) que busca exotizar y delinear la alteridad en términos dicotómicos, sin bucear en las desigualdades y heterogeneidades que los atraviesa en todas sus dimensiones ¿Dónde empieza y termina lo "cultural" y "ancestral" como derecho en estas políticas interculturales? ¿cuál es el límite de la alteridad entendida incluso como dicotomía? ¿Será recuperando reflexiones sugeridas por Hale (2004)- que la dicotomía sólo es posible cuando no se constituye en una argumentación política radical que pone en entredicho intereses económicos; o bien -siguiendo ciertas discusiones que plantea Marisol de la Cadena (De la Cadena, Risor y Feldman, 2018)- que la dicotomía se vuelve distópica cuando se configura en un argumento político que contraviene en un mismo movimiento intereses económicos, marcos de entendimiento y formas de pensar y hacer mundo que no se configuran por los mismos criterios que dividen naturaleza-cultura, vivosmuertos, humanos-no humanos?

Sin duda, el patrimonio instituido en materia indígena habita los bordes de la interculturalidad como política y configura sus desmesuras. El reconocimiento estatal de algunos saberes, producciones culturales, memorias, sacralidades entendidas como patrimonios dentro de una política de derechos humanos estandarizada se asienta en la imposibilidad de pensar prácticas, relaciones y conceptualizaciones que desborden e interpelen las bases epistémicas, cosmovisionales y territoriales universalizadas por el capitalismo occidental. Como fui desagregándolo a lo largo de este escrito, más que contradictorias, extrañas o antitéticas, la política de derechos humanos esgrimida contuvo vasos vinculantes y potencialmente capitalizables en varios sentidos con la política represiva y la judicialización desatada sobre algunos mapuche en nuestro país en esos años.

\section{Bibliografía}

Anaya, J. (2012). Informe del Relator Especial sobre los derechos de los pueblos indígenas. La situación de los pueblos indígenas en Argentina. A/HRC/21/47/Add.2., 4 de julio de 2012. http://acnudh.org/wp-content/uploads/2012/09/ Informe-del-Relator-sobre-derechos-de-pueblosind\%C3\%ADgenas-misi\%C3\%B3n-a-Argentina-2012.pdf

Barros, M. y Quintana, M. M. (2019). Notas sobre el discurso del "amor" (y el odio) en Cambiemos. Bordes, revista de política, derecho y sociedad. http:// revistabordes.com.ar/notas-sobre-el-discurso-del-amory-el-odio-en-cambiemos/

Barveri, P. (2015). La ley 26.160 como política pública orientada a la protección de la propiedad comunitaria indígena: algunos avances y desafíos pendientes. En F. Kosovsky y S. L. Ivanoff (Comp.); Propiedad comunitaria indigena (pp. 101-122). Comodoro Rivadavia. Universitaria de la Patagonia: EDUPA.

Boccara G. (2012). La interculturalidad como campo. Cuadernos interculturales, 10(18), 11-30.

Braticevic, S. I., y Cabana, J. L. (2014). Aplicación de políticas públicas orientadas a Pueblos Indígenas: un 
análisis comparativo del avance de la frontera agraria y sus contradicciones con el Programa de Relevamiento de la Ley 26.160. Revista Estado y Políticas Públicas, № 2,187-204.

Briones, C. (2015). Políticas indigenistas en Argentina: entre la hegemonía neoliberal de los años noventa y la 'nacional y popular' de la última década. Antípoda, 21, 21-48.

Comaroff, J. L. y Comaroff, J. (2011). Etnicidad S.A. Buenos Aires: Katz.

Cardin, L. (2013). La comunidad qom Potae Napocna Navogoh (La Primavera) y el proceso de lucha por la restitución de su territorio. En Actas de las $X$ Jornadas de Sociología. Buenos Aires: Facultad de Ciencias Sociales, Universidad de Buenos Aires. http://cdsa.aacademica. org/000-038/354.pdf

Crespo, C. (2016). Processes of indigenous heritage construction: Lines of discussion, axes of analysis and Methodological approaches. En O. Kaltmeier y M. Rufer (Eds.), Entangled Heritages. (Post)Colonial Perspectives on the Uses of the Past in Latin America (pp. 153-174). Londres: Routledge.

Crespo, C., Losada, F. y Martín, A. (2007). Introducción. En C. Crespo, F. Losada y A. Martín (Eds.), Patrimonio, políticas culturales y participación ciudadana (pp. 5-11). Buenos Aires: Antropofagia.

de Sousa Santos, B. (2002). Hacia una concepción multicultural de los derechos humanos. El Otro Derecho, 28, 60-83.

Delrio, W. (2018). La lucha de los mapuches y sus estereotipos. Nueva Sociedad. https://ri.conicet.gov. ar/bitstream/handle/11336/67461/CONICET_Digital_ Nro.d6491ad9-700d-4c43-9683-a0a2e05d647e_A. pdf? sequence $=28$ isAllowed $=\mathrm{y}$

De la Cadena, M., Risor, H. y Feldman, J. (2018). Aperturas onto-epistémicas: conversaciones con Marisol de la Cadena. Antípoda. Revista de Antropología y Arqueología, 32, 159-177.

Gnecco, C. (2005). Ampliación del campo de batalla. Textos Antropológicos, 15(2), 183-195.

Hale, C. (2004). El protagonismo indígena, las políticas estatales y el nuevo racismo en la época del "indio permitido". En Construyendo la paz: Guatemala desde un enfoque comparado. Conferencia organizada por la Misión de Verificación de las Naciones Unidas en Guatemala (MINUGUA), 27-29 de octubre. https:// es.scribd.com/doc/80823895/Hale-protagonismaindigena-politicas-estatales-y-nuevo-racismo-enmulticulturalismo-neoliberal

Hall, S. (1997). La centralidad de la cultura: notas sobre las revoluciones culturales de nuestro tiempo. En K. Thompson (Ed.), Media and Cultural Regulation (London, Thousand Oaks, New Delhi: The Open University; Sage Publications), de la colección Culture, Media and Identities, editada por la Open University. Traducción: Jorge Cáceres Riquelme y Hugo Herrera Pardo. https:// www.academia.edu/39737531/_Traducci\%C3\%B3n_ Stuart_Hall._La_centralidad_de_la_cultura._Notas_ sobre_las_revoluciones_culturales_de_nuestro_tiempo

Kirshenblatt-Gimblett, B. (2004). Intangible Heritage as Metacultural Production. Museum international 2004, 56 (1-2), 52-65.

Lenton, D. (2010). Política indigenista argentina: una construcción inconclusa. Anuário antropológico, (I), 57-97.

Macdonald, S. (2013). Heritage. En International Encyclopedia of Anthropology. Editado por H. Callon, New Yersey, United States: John Wiley \& Sons Ltd. Wiley Online Library: https://onlinelibrary.wiley.com/doi/ book/10.1002/9781118924396

Minieri, R. (2006). Ese Lejano Sur. Un dominio Británico de un millón de hectáreas en la Patagonia. Viedma: Fondo Editorial Rionegrino.

Pabón Cadavid, J, A. (2018). Participación de comunidades y el camino hacia un Derecho Humano al Patrimonio Cultural. Estudios constitucionales, 16 (29), 89-116.

Perez-Prat, L. (2014). Observaciones sobre el Derecho al Patrimonio Cultural como Derecho Humano. Periférica Internacional, Revista para el Análisis de la Cultura y el Territorio, 15, 319-342.

Ramos, A. (2018). Ser pobre, joven y mapuche. El asesinato de Rafael Nahuel y la represión en Patagonia. Revista Anfibia. http://revistaanfibia.com/ensayo/serjoven-pobre-mapuche/

Reygadas, L. (2014). Equidad Intercultural. En P. Sandoval (Ed.), Diversidad Cultural, Desarrollo y Cohesión Social (pp. 16-33). Lima: Ministerio de Cultura.

Rufer, M. (2014). La exhibición del otro: tradición, memoria y colonialidad en museos de México. Antítesis, 7 (14), 94-120.

Smith, L. (2012). Discourses of heritage: implications for archaeological community practice. Nuevo Mundo Mundos Nuevos. http://journals.openedition.org/ nuevomundo/64148 Consultado el 20 de enero 2017.

Soria, S. (2019). Políticas indigenistas en la Argentina kirchnerista. Iconos, 64, 203-220.

Walsh, C. (2010). Interculturalidad crítica y educación intercultural. Construyendo interculturalidad crítica, 75, 96. file:///C:/Users/PC/Downloads/interculturalidad\%20 critica\%20y\%20educacion\%20intercultural\%20(1).pdf 